Bull. Fac. Agric., Cairo Univ., 59 (2008): 249-258.

\title{
EVALUATION OF PEDOTRANSFER FUNCTIONS (PTFs) IN PREDICTING UPPER AND LOWER LIMITS OF SOIL WATER CONTENTS
}

(Received: 21.2.2008)

\author{
By \\ O. E. Mohawesh \\ Department of Plant Production, Faculty of Agriculture, Mu'tah University, Al-Karak, Jordan
}

\begin{abstract}
Knowledge of upper and lower limits of soil water content (ULSWC, LLSWC) is indispensable to calculate the water depth that should be applied by irrigation, and to determine water availability, which is a crucial factor in assessing the suitability of a land area to produce a given crop. However, direct measuring of these limits is time consuming and expensive. Several attempts have been made to establish a relation between readily available soil properties, like particle-size distribution, organic matter, and bulk density and ULSWC, LLSWC. These relationships are referred to as pedotransfer functions (PTFs). Therefore, the objective of this study was to evaluate some PTFs with respect to their accuracy in predicting the two limits of soil water content for some Jordanian agricultural soils. Fourteen widely used PTFs were selected for evaluation. Eight of the selected PTFs predict soil water content at certain matric potential, whereas the others predict water retention function parameters. In order to quantify the prediction accuracy, the mean error (ME), the root mean square error (RMSE), unbiased root mean square error (URMSE), and the Pearson correlation ( $\mathrm{r}$ ) were used. The PTFs showed good to poor prediction accuracy with RMSE ranging from 0.00149 to $0.03789 \mathrm{~m}^{3} \mathrm{~m}^{-3}$, ME values ranging from -0.01560 to $0.26785 \mathrm{~m}^{3} \mathrm{~m}^{-3}$ and with URMSE ranging from 0.00017 to $0.00331 \mathrm{~m}^{3} \mathrm{~m}^{-3}$. The validation indices showed that British soil survey (topsoil and subsoil), and Rawls-Brakensiek were found as the best method to calculate the limits of soil water content for the evaluated Jordanian soil data set. Rosetta exhibited an intermediate value in estimation of soil moisture limits of the evaluated soil set. The implementation of soil bulk density as an extra input value did not improve the accuracy of the estimated soil water content limits. This may be due to the fact that more input data are required in our soil set.
\end{abstract}

Key words: accuracy, artificial neural network, pedotransfer functions, regression, upper and lower limits of soil water content.

\section{INTRODUCTION}

Soil water contents at lower and upper limits (LLSWC, ULSWC) are used to calculate the water depth that should be applied by irrigation (Hansen et al., 1980), and to determine water availability, which is a crucial factor in assessing the suitability of a land area for the production of a given crop ( Sys et al., 1991). If the area under investigation is relatively small or known to be quite homogeneous with respect to soil physical properties and topography, determinations of LLSWC and ULSWC at a reasonable number of sampling sites should provide accurate estimates. However, if the area being evaluated is large enough to exhibit substantial spatial variability of soil water variability, it is virtually impossible to perform enough measurements to provide good estimates within the temporal and financial constraints of the project. Since measurement of soil water contents limits are cumbersome and time consuming, the number of measured hydraulic property data is usually limited, and is usually less than required to fully characterize soil heterogeneity. Hence, a simple technique is being needed to estimate soil water limits as tools for describing the spatial variability of such properties (Schaap et al., 2001). Many indirect methods for estimating of soil water contents have been developed. These methods are called pedotransfer functions (PTFs) (Bouma and van Lanen, 1987). Bouma (1989) introduced the term PTFs, which he described as translating data that we have (soil survey data) into data that we need (soil hydraulic data). These are generally empirical relationships that allow the hydraulic properties of a given soil to be predicted from more widely available data, usually soil texture, bulk density and organic matter or carbon content. However, since every PTF is developed on the basis of a data base of a 
limited number of soil samples, it is not always clear to what extend these functions can be used in the case of soil conditions other than those under which they were developed (Donatelli et al., 1996 and Wösten et al., 1999). Moreover, the available PTFs can produce substantially different estimates. Thus, scientists have a difficult task in selecting a more appropriate PTF for their application (Acutis and Donatelli, 2003).

PTFs are classified as point estimation methods and parametric estimation methods (Tietje and Tapkenhinrichs, 1993). Point estimation methods follow a direct approach by estimating water content at predetermined pressure heads. Many examples of this type of PTF exist, i.e., Gupta and Larson (1979), Rawls et al. (1982), Minasny et al. (1999), and Tomasella et al. (2003). Parametric methods estimate the parameters of water retention functions, such as the Brooks and Corey (1964), Campbell (1974), and van Genuchten (1980) equations. A recent approach for fitting PTFs is the use of artificial neural networks (Pachepsky et al., 1996 and Schaap et al., 1998). An advantage of using the artificial neural networks (ANN) approach is that no relationships need to be assumed before hand. Instead the network is trained to find the relationship. Schaap and Leij (2000) developed Rosetta computer program that implemented some of the models published by Schaap and Bouten (1996), and Schaap et al. (1998). Other programs developed to estimate soil hydraulic properties include: EURM3 (Nemes et al., 2003), SOILPAR2 (Acutis and Donatelli, 2003), SWLIMITS (Ricthie et al., 1999). ROSETTA and EUR-M3 use an ANN for prediction and the bootstrap to perform uncertainty analysis. SOILPAR2 is a program for estimating soil hydraulic properties using empirical equations.

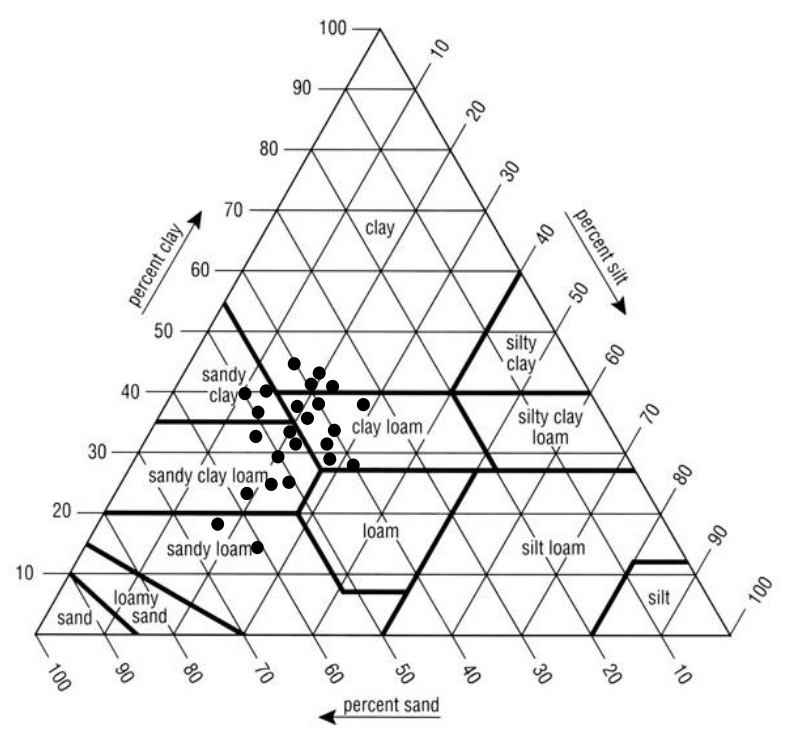

The aims of the current study were to evaluate the general applicability and the prediction accuracy of some of the most commonly cited and some recently developed PTFs that use soil properties such as particle-size distribution (sand, silt, and clay), organic matter content or organic C content, and dry bulk density to predict LLSWC and ULSWC for some Jordanian agricultural soils.

\section{MATERIALS AND METHODS \\ 2.1. Soil samples collection and analysis}

The evaluation of the PTFs in this study was based on data set of Twenty four undisturbed soil samples 0.05 in diameter and $0.051 \mathrm{~m}$ in height $\left(100 \mathrm{~cm}^{3}\right)$, collected from different soils covering a wide range of texture classes throughout Jordan (Fig. 1). The samples LLSWC and ULSWC were measured with pressure chambers (Soil moisture equipment, Santa Barbara, CA) at -33 and -1500 $\mathrm{KPa}$, respectively. Once ULSWC and LLSWC were measured, bulk density (BD), organic matter $(\mathrm{OM})$ and particle-size distribution (PSD) in three fractions were determined. PSD was determined with hydrometer method (Gee and Bauder, 1986). OM was determined by Walkley and Black method (Walkley and Black, 1934), while BD was measured from weighing the undisturbed soil samples after LLSWC and ULSWC were measured by drying the soil samples for more than $24 \mathrm{~h}$ at $105^{\circ} \mathrm{C}$.

\subsection{Pedotransfer functions}

The PTFs are subdivided into two groups. The first includes point PT, which estimates water contents at specific pressure values and/or ULSWC and LLSWC and saturated hydraulic conductivity. The second includes function PT, which estimates the parameters according to widely used soil retention functions: Campbell model (CP), Huston-Cass model (HC), Brooks and Corey model (BC), and van Genuchten model (vG).

\subsubsection{Point pedotransfer functions}

The point PTFs, which were used in the study, are: (i) Brakensiek-Rawls, (ii) Hutson, (iii) British soil survey (topsoil and subsoil), (iv) Baumer, (v) Rawls, and (vi) Manrique. The PTFs input and outputs are reported in Table 1.

\subsubsection{Function pedotransfer functions}

Function PTFs, which were used in the study, include:

(i) Campbell (Campbell, 1985)

The methods estimate the coefficient of the Campbell retention function on the basis of the geometric mean and standard deviation of the particle size and bulk density, using the following

Fig. (1): Soil texture classes $\mu$ the evaluating soil samples. 
equation:

$$
\psi_{m}=\psi_{e}\left(\frac{\theta_{a c t}}{\theta_{s}}\right)^{-b}
$$

where $\psi_{m}$ is the pressure corresponding to $\theta_{a c t}$, $\psi_{e}$ the pressure at air entry point; $b$ the empirical coefficient; $\theta_{s}$ is the water content at saturation; and $\theta_{a c t}$ is the actual soil water content. The parameters are estimated according to the following equations:

$$
\begin{aligned}
& b=2 \times 0.5_{d 50}^{-1 / 2}+0.2 \sigma_{g} \\
& \psi_{e}=-0.5_{d 50}^{-1 / 2}(B D / 1.3)^{0.67 b}
\end{aligned}
$$

where $\mathrm{d}_{50}$ is the median diameter and $\sigma_{g}$ the geometric standard deviation of particles diameter. The soil water content limits (ULSWC, LLSWC) are obtained by the Campbell equation evaluation.

(ii) Mayr- Javris (Mayr and Javris, 1999). This

$$
\begin{aligned}
& \psi_{m}=\psi_{e}[2 b /(1+2 b)]^{-b} \\
& \theta_{c}=2 b \theta_{s} /(1+2 b)
\end{aligned}
$$

All the symbols have the same meaning of those used in Campbell's retention function. The ULSWC and LLSWC are obtained by the HutsonCass function evaluation.

(iii) Rawls-Brakensiek (Rawls and Brakensiek, 1989).

This method estimates the parameters of the Brooks-Corey retention function using sand, clay, and bulk density. The Brooks-Corey retention equation (1964) is the following:

$$
\theta(h)=\theta_{r}+\frac{\theta_{s}-\theta_{r}}{\left(h_{b} / h\right)^{\lambda}}
$$

where $h_{b}$ is the air entry value; $\lambda$ is the pore size index; $\theta_{r}$ is the residual water content and their parameters are estimated using empirical equations.

(iv) van Genuchten (van Genuchten, 1980)

Table (1): Overview of the most important characteristics of the evaluated PTFs in this study.

\begin{tabular}{|l|c|c|c|}
\hline \multicolumn{1}{|c|}{ Model } & $\begin{array}{c}\text { Required input } \\
\text { data }\end{array}$ & Parameters estimated & Reference \\
\hline Brakensiek-Rawls & PSD, OC, BD & SWC & Hutson and Wagenet, 1992 \\
\hline Hutson & PSD, OC, BD & SWC & Hutson and Wagenet, 1992 \\
\hline $\begin{array}{l}\text { British soil survey } \\
\text { topsoil and subsoil) }\end{array}$ & PSD, OC, BD & SWC & Hutson and Wagenet, 1992 \\
\hline Baumer & PSD, OC & BD, ULSWC, LLSWC & ASW/EPIC \\
\hline Rawls & PSD & BD, ULSWC, LLSWC & ASW/EPIC \\
\hline Manrique & PSD, BD & ULSWC, LLSWC & ASW/EPIC \\
\hline Campbell & PSD, BD & CA parameters & Campbell, 1985 \\
\hline Mayr- Javris & PSD, OC, BD & HC parameters & Mayr and Jarvis, 1999 \\
\hline Rawls-Brakensiek & PSD, Porosity & BC parameters & Rawls and Brakensiek, 1989 \\
\hline Vereecken & PSD, OC, BD & vG parameters & Vereecken et al., 1989 \\
\hline HYPRES & PSD, OM, BD & vG parameters & Wösten et al., 1999 \\
\hline Rosetta (H2) & PSD & vG parameters & Schaap et al., 2001 \\
\hline Rosetta (H3) & PSD, BD & vG parameters & Schaap et al., 2001 \\
\hline
\end{tabular}

PSD: particle size distribution; OC: organic carbon (\%); OM: organic matter (\%); BD: bulk density ( $\left.\mathrm{m} \mathrm{m}^{-3}\right)$; ULSWC: soil water content at upper limit $\left(\mathrm{m}^{3} \mathrm{~m}^{-3}\right)$; LLSWC: soil water content at lower limit $\left(\mathrm{m}^{3} \mathrm{~m}^{-3}\right)$; SWC: soil water content at several pressures; Porosity: the authors propose to obtain porosity from (1-BD/2.65); CA: Campbell retention function; HC: Hutson-Cass retention function; BC: Brooks-Corey retention function; vG: van Genuchten retention function.

method estimates the parameters of the HutsonCass retention equation. The Hutson-Cass (Hutson and Cass, 1987) retention equation is:

$$
\psi_{m}=\left\{\begin{array}{l}
\frac{a\left(1-\theta_{a c t} / \theta_{s}\right)^{1 / 2}\left(\theta_{c} / \theta_{s}\right)^{-b}}{\left(1-\theta_{c} / \theta_{s}\right)^{1 / 2}}, 0 \leq \psi_{m} \leq \psi_{c} \\
\psi_{e}\left(\frac{\theta_{a c t}}{\theta_{s}}\right), \psi_{m}>\psi_{c}
\end{array}\right.
$$

where
The PTFs Vereecken (Vereecken et al., 1989); HYPRES (Wösten et al., 1999); Rosetta (Schaap et al., 2001)) evaluated the parameters of the vG retention equation:

$$
\theta(h)=\theta_{r}+\frac{\theta_{s}-\theta_{r}}{\left[1+(\alpha h)^{n}\right]^{m}}
$$

Rosetta is able to estimate the $\mathrm{vG}$ water retention parameters and saturated hydraulic conductivity, as well as unsaturated hydraulic conductivity parameters, based on Mualem's 
(1976) pore-size model. Rosetta implements five hierarchical PTFs for the estimation of water retention, and the saturated and unsaturated hydraulic conductivity using limited to more extended input data. Rosetta is based on neural network analyses combined with bootstrap method. Thus allowing the program to provide uncertainty estimates of the predicted hydraulic parameters. The PTFs input and outputs are reported in Table (1).

\subsection{Evaluation criteria}

Four criteria were used to quantify errors in the PTF estimates of the soil water contents: the root mean square error (RMSE), mean error (ME), unbiased root mean square error (URMSE), and the correlation coefficient (r). The most commonly used criteria in PTF-related work is probably RMSE, which defined as:

$$
R M S E=\sqrt{\frac{1}{n} \sum_{i=1}^{n}\left(\theta_{\text {esti }}-\theta_{\text {meas }}\right)^{2}}
$$

where $\mathrm{n}$ is the number of observations for which the RMSE is computed, and $\theta_{\text {meas }}, \theta_{\text {esti }}$ are measured and estimated soil water contents, respectively. The RMSE may be viewed as giving the accuracy of the model in terms of standard deviations. When systematic errors exist, the RMSE are biased and do not reflect the true zeromean variance. Systematic errors are often an artifact of the calibration database (Schaap and Leij, 1998) and could render a comparison of PTFs based on RMSE values difficult. Therefore, we decompose the RMSE into ME and URMSE (Hastie et al., 2001). ME may be used to quantify systematic errors between measurements and PTF estimations as:

$$
M E=\frac{1}{n} \sum_{i=1}^{n}\left(\theta_{\text {esti }}-\theta_{\text {meas }} .\right)
$$

ME values are negative when the PTF underestimates water content. URMSE values were used by Tietje and Hennings (1996) and have the mean errors removed as:

$$
\text { URMSE }=\sqrt{\frac{1}{n} \sum_{i=1}^{n}\left[\left(\theta_{\text {esti }}-M E\right)-\theta_{\text {meas } .}\right]^{2}}
$$

The value of the model correlation depends on one basic index, which is the correlation coefficient $r$ (Addiscott and Whitmore, 1987). The coefficient $r$ is derived from the Pearson's linear correlation coefficient.

\section{RESULTS AND DISCUSSION}

The values calculated for the different validation indices of estimating ULSWC and LLSWC using PTFs are given in Tables (2 and 3), respectively. The PTFs performance for estimating ULSWC and LLSWC as estimated vs. measured values are shown in Figs. (2 and 3). Ideally the intercept should be close to zero, however, the intercept for ULSWC and LLSWC ranged from 0.1882 to 0.3933 and -0.0849 to 0.1584 , respectively. The closest PTFs model to zero intercept was Buamer and Rosetta (H2) for ULSWC and LLSWC estimation, respectively. Similarly, the slope should be close to 1 , however, the slope for ULSWC and LLSWC ranged from 0.1092 to 1.9222 and 0.4045 to 6.1932 , respectively. The closest PTFs to 1 slope were Buamer and HYPRES for ULSWC and LLSWC estimation, respectively. However, such statistical testing of intercept and slope is much more rigorous and sometimes misleading (Givi et al., 2004), and so another evaluation criteria were used to evaluate PTFs performance.

A correlation coefficient (r) was used to reflect how good the estimated data match with the measured ones. RMSE, ME, and UMRSE also represent the deviation of the estimated values from the observed ones, and it does in a more comprehensive manner (Kobayashi and Salam, 2000). The inference drawn on the basis of just correlation coefficient can be erroneous. The $r$ values reveal a somewhat different pattern in terms of the models validity. The correspondence between measured and estimated values is still high for the British soil survey (topsoil and subsoil). However, poor correspondence is observed for the PTF of Vereecken. In the case of LLSWC, the correlation values are satisfactory for most PTFs (Table 3). Although, the correlation of Mayr-Javris is high, its RMSE, ME, and UMRSE are the highest values among the evaluated PTFs. Like the results of ULSWC, although URMSE is relatively low for Vereecken, the correlation between the measured and estimated values is the poorest. Therefore, correlation coefficient and ME, RMSE, and UMRSE values should be used in evaluating PTFs.

When considering ME, it can be observed that only Vereecken PTF tend to overestimate the estimated ULSWC and LLSWC (Tables 2 and 3). This is in agreement with the findings of Kern (1995). He reported a slightly to overestimate LLSWC in case of Vereecken PTF. The other PTFs show a tendency to underestimate the estimated values. As regards the ME, British soil survey (topsoil) and Mayr-Javris show the minimum and the maximum ME for estimation 
ULSWC, while British soil survey (subsoil) and Mayr-Javris exhibit the minimum and maximum ME for estimation LLSWC, respectively.

As regards RMSE, again British soil survey (subsoil and topsoil) showed the lowest values, meaning that the estimated ULSWC and LLSWC values follow the measured relatively well. By far the highest values resulted from the Mayr-Javris PTF. The other PTFs have intermediate values. As concerns UMRSE, a different trend can be perceived: the PTF of Rawls-Brakensiek shows the lowest value for estimated ULSWC and LLSWC. The highest relatively value exhibited by Mayr-Javris PTF.
In the evaluation criteria based analysis, the best PTFs for estimating of ULSWC and LLSWC are: British soil survey (topsoil), British soil survey (subsoil), and Rawls-Brakensiek. This corroborates the results obtained by Donatelli et al. (1996). Many researchers emphasize that PTFs should be applied to soils whose characteristics are similar to those of the soils from which the PTFs were derived (Cornelis et al., 2001; Mayr and Javris, 1999 and Nemes et al., 2002). In the development of British soil survey (topsoil and subsoil) and Rawls-Brakensiek PTFs, mainly soils similar to our data set were used in development of these PTFs.

Table (2): Evaluation of the PTFs for estimating upper limits of soil water content (ULSWC).

\begin{tabular}{|l|c|c|c|c|c|c|}
\hline PTFs & RMSE & ME & UMRSE & r & Intercept & Slope \\
\hline Brakensiek-Rawls & $\mathbf{0 . 0 0 2 6 6}$ & $\mathbf{- 0 . 0 5 1 4 4}$ & $\mathbf{0 . 0 0 1 3 3}$ & $\mathbf{0 . 5 9}$ & $\mathbf{0 . 0 5 9 4} *$ & $\mathbf{0 . 9 7 4 7} *$ \\
\hline Hutson & $\mathbf{0 . 0 0 2 9 1}$ & $\mathbf{- 0 . 0 5 5 6 0}$ & $\mathbf{0 . 0 0 1 3 6}$ & $\mathbf{0 . 6 1}$ & $\mathbf{- 0 . 0 7 1 0}$ & $\mathbf{1 . 4 0 8 8}^{*}$ \\
\hline British soil survey (topsoil ) & $\mathbf{0 . 0 0 1 4 9}$ & $\mathbf{- 0 . 0 1 5 6 0}$ & $\mathbf{0 . 0 0 1 3 7}$ & $\mathbf{0 . 6}$ & $\mathbf{- 0 . 0 9 8 0}$ & $\mathbf{1 . 3 2 5 1}^{*}$ \\
\hline British soil survey (subsoil ) & $\mathbf{0 . 0 0 4 3 3}$ & $\mathbf{- 0 . 0 7 6 4 4}$ & $\mathbf{0 . 0 0 1 4 0}$ & $\mathbf{0 . 5 7}$ & $\mathbf{0 . 0 4 1 4}$ & $\mathbf{1 . 1 2 1 4}^{*}$ \\
\hline Baumer & $\mathbf{0 . 0 0 1 6 4}$ & $\mathbf{- 0 . 0 2 8 5 2}$ & $\mathbf{0 . 0 0 1 2 3}$ & $\mathbf{0 . 6 4}$ & $\mathbf{0 . 0 2 4 6} *$ & $\mathbf{1 . 0 1 1 6}^{*}$ \\
\hline Rawls & $\mathbf{0 . 0 0 4 3 4}$ & $\mathbf{- 0 . 0 7 7 2 7}$ & $\mathbf{0 . 0 0 1 3 5}$ & $\mathbf{0 . 6 7}$ & $\mathbf{- 0 . 1 8 8 2}$ & $\mathbf{1 . 9 2 2 2}^{*}$ \\
\hline Manrique & $\mathbf{0 . 0 0 8 5 6}$ & $\mathbf{- 0 . 1 0 8 1 0}$ & $\mathbf{0 . 0 0 2 7 2}$ & $\mathbf{- 0 . 0 6}$ & $\mathbf{0 . 3 9 3 3} *$ & $\mathbf{- 0 . 1 0 9 2} *$ \\
\hline Campbell & $\mathbf{0 . 0 0 2 8 7}$ & $\mathbf{- 0 . 0 4 1 0 2}$ & $\mathbf{0 . 0 0 2 0 3}$ & $\mathbf{0 . 2 8}$ & $\mathbf{0 . 1 9 3 6} *$ & $\mathbf{0 . 5 2 9 3} *$ \\
\hline Mayr-Javris & $\mathbf{0 . 0 2 0 9 5}$ & $\mathbf{- 0 . 1 9 5 6 0}$ & $\mathbf{0 . 0 0 1 8 1}$ & $\mathbf{0 . 3 8}$ & $\mathbf{0 . 0 8 1 6} *$ & $\mathbf{1 . 6 7 2 1}^{*}$ \\
\hline Rawls-Brakensiek & $\mathbf{0 . 0 0 3 8 4}$ & $\mathbf{- 0 . 0 7 2 2 7}$ & $\mathbf{0 . 0 0 1 2 2}$ & $\mathbf{0 . 6 4}$ & $\mathbf{0 . 0 6 1 4} *$ & $\mathbf{1 . 0 3 7 0}^{*}$ \\
\hline Vereecken & $\mathbf{0 . 0 0 4 2 5}$ & $\mathbf{0 . 0 4 7 3 1}$ & $\mathbf{0 . 0 0 3 1 3}$ & $\mathbf{0 . 0 2}$ & $\mathbf{0 . 3 8 2 3} *$ & $\mathbf{- 0 . 0 4 1 4} *$ \\
\hline HYPRES & $\mathbf{0 . 0 0 2 3 9}$ & $\mathbf{- 0 . 0 1 6 2 8}$ & $\mathbf{0 . 0 0 2 2 6}$ & $\mathbf{0 . 1 6}$ & $\mathbf{0 . 2 5 8 0}$ & $\mathbf{0 . 3 0 7 2}$ \\
\hline Rosetta (H2) & $\mathbf{0 . 0 0 6 7 7}$ & $\mathbf{- 0 . 1 0 4 3 7}$ & $\mathbf{0 . 0 0 1 3 2}$ & $\mathbf{0 . 6 7}$ & $\mathbf{- 0 . 1 0 0 3} *$ & $\mathbf{1 . 7 8 4 8}^{*}$ \\
\hline Rosetta (H3) & $\mathbf{0 . 0 0 6 1 8}$ & $\mathbf{- 0 . 0 9 4 5 3}$ & $\mathbf{0 . 0 0 1 7 1}$ & $\mathbf{0 . 4 1}$ & $\mathbf{0 . 0 8 1 5 *}$ & $\mathbf{1 . 0 4 8 0}^{*}$ \\
\hline
\end{tabular}

RMSE: root mean square error $\left(\mathrm{m}^{3} \mathrm{~m}^{-3}\right)$, ME: mean error $\left(\mathrm{m}^{3} \mathrm{~m}^{-3}\right)$, UMRSE: unbiased root mean square error $\left(\mathrm{m}^{3} \mathrm{~m}^{-3}\right), \mathrm{r}$ : Pearson correlation.

* Significant at 0.05 probability level.

Table (3): Evaluation of the PTFs for estimating lower limits of soil water content (LLSWC).

\begin{tabular}{|c|c|c|c|c|c|c|}
\hline PTFs & RMSE & ME & UMRSE & $\mathbf{r}$ & intercept & Slope \\
\hline Brakensiek-Rawls & 0.00743 & -0.11076 & 0.00130 & 0.72 & $0.0210 *$ & 1.4491* \\
\hline Hutson & 0.00609 & -0.09576 & 0.00151 & 0.68 & $-0.0638 *$ & $1.7421 *$ \\
\hline British soil survey (topsoil ) & 0.00635 & -0.09993 & 0.00136 & 0.75 & $-0.0849 *$ & $1.8766 *$ \\
\hline British soil survey (subsoil ) & 0.00293 & -0.05868 & 0.00121 & 0.73 & $-0.0245 *$ & $1.3302 *$ \\
\hline Baumer & 0.00468 & -0.08285 & 0.00125 & 0.7 & $0.0558 *$ & $1.1186 *$ \\
\hline Rawls & 0.00948 & -0.12826 & 0.00125 & 0.73 & $0.0544 *$ & $1.4046 *$ \\
\hline Manrique & 0.01411 & -0.15951 & 0.00139 & 0.73 & $0.0355 *$ & 1.8198* \\
\hline Campbell & 0.00599 & -0.09535 & 0.00145 & 0.66 & 0.0093* & 1.3994* \\
\hline Mayr- Javris & 0.03789 & -0.26785 & 0.00017 & 0.75 & $0.0450 *$ & 6.1932* \\
\hline Rawls-Brakensiek & 0.00808 & -0.11785 & 0.00114 & 0.78 & $0.0064 *$ & $1.5777 *$ \\
\hline Vereecken & 0.00523 & 0.06590 & 0.00305 & 0.47 & $0.1584 *$ & $0.4045 *$ \\
\hline HYPRES & 0.00969 & -0.12791 & 0.00151 & 0.61 & 0.1246* & 1.0180* \\
\hline Rosetta (H2) & 0.01660 & -0.17333 & 0.00158 & 0.71 & $0.0046 *$ & $2.2276 *$ \\
\hline Rosetta (H3) & 0.01747 & -0.17758 & 0.00170 & 0.64 & 0.0393* & 2.0383* \\
\hline
\end{tabular}

RMSE: root mean square error $\left(\mathrm{m}^{3} \mathrm{~m}^{-3}\right)$, ME: mean error $\left(\mathrm{m}^{3} \mathrm{~m}^{-3}\right)$, UMRSE: unbiased root mean square error $\left(\mathrm{m}^{3} \mathrm{~m}^{-3}\right)$, r: Pearson correlation.

* Significant at 0.05 probability level. 

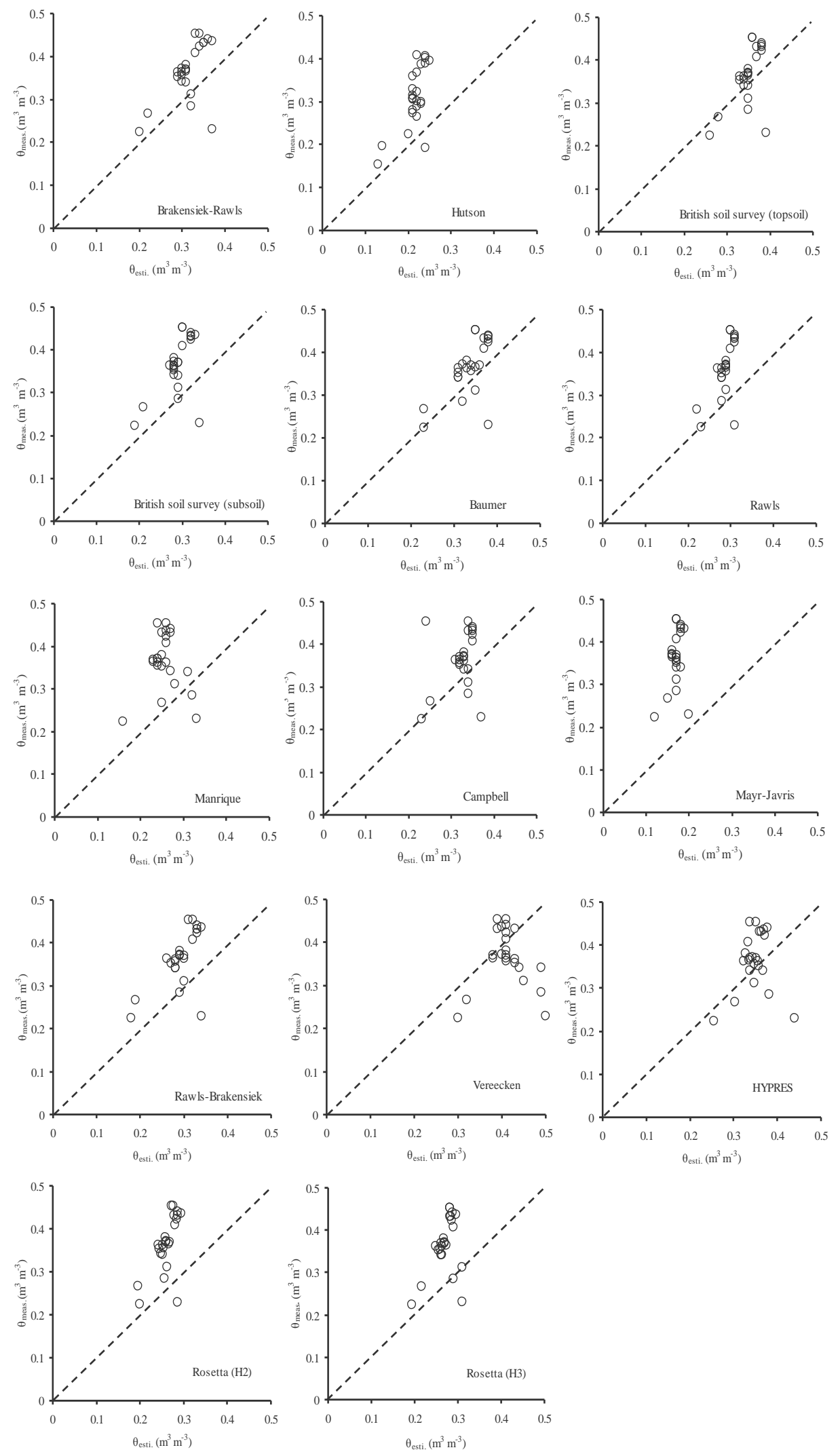

Fig. (2): Pedotransfer functions estimates of upper limits of soil water content (ULSWC) vs. measured values. 

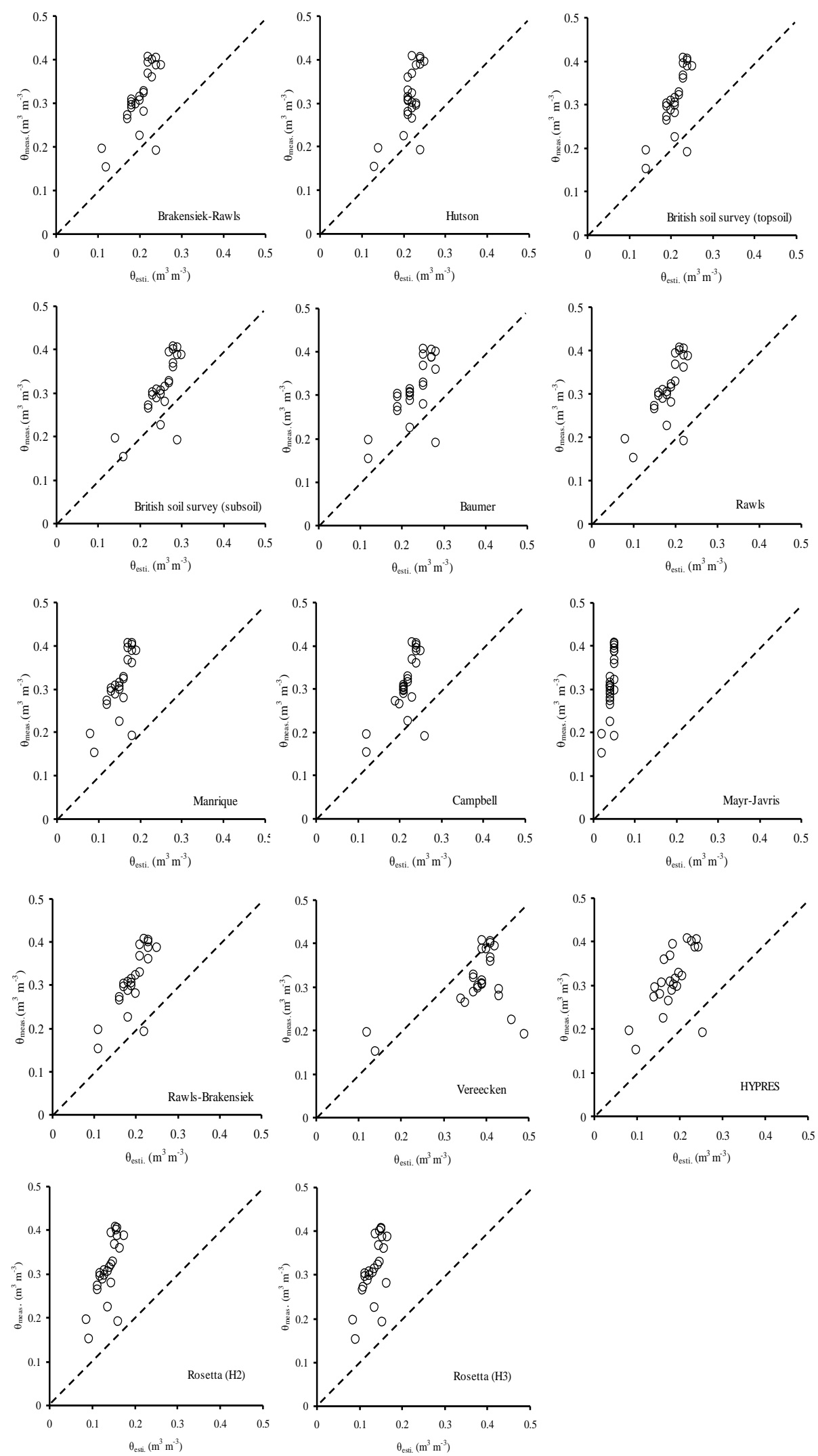

Fig. (3): Pedotransfer functions estimates of lower limits of soil water content (LLSWC) vs. measured values. 


\section{Conclusions}

The evaluation and comparison of fourteen pedotransfer functions that were considered in this study enabled us to draw the following conclusions: the PTFs of British soil survey (topsoil and subsoil), and Rawls-Brakesiek were most accurate for our evaluation data set to estimate upper and lower limits of soil contents of Jordanian evaluated soils. It had the highest ranking for the four validation indices that were computed in this study. The low performance of Rosetta and HYPRES PTFs might be due to the fact that the soils used in its development were different from our soils. The implement of soil bulk density in Rosetta as an extra input value did not improve the accuracy prediction of our evaluated soil set. The results also, indicate that the upper and lower limits of soil water content can be estimated for soils where the laboratory measurements are not available. However, a local evaluation is being needed before using any available PTFs. Because the data set used in our evaluation does not cover homogeneously the whole of Jordan (and probably does not include all the soil types), further studies will be necessary to assess the validity of the estimation.

\section{REFERENCES}

Acutis M. and Donatelli M. (2003). SOILPAR 2.00: Software to estimate soil hydrological parameters and functions. Eur. J. Agron. 18: 373-377.

Addiscott T.M. and Whitmore A.P. (1987). Computer simulation of changes in soil mineral nitrogen and crop nitrogen during autumn, winter and spring. J. Agric. Sci. 109: 141-157.

Bouma J. (1989). Using soil survey data for quantitative land evaluation. Adv. in Soil Sci. 9: 177-213.

Bouma J. and van Lanen H.A.J. (1987). Transfer functions and threshold values: from soil characteristics to land qualities. In Quantified land evaluation. Proc. of a workshop by ISSS/SSSA. ITC, Enschede, The Netherlands, 6,106-111.

Brooks R.H. and Corey A.T. (1964). Hydraulic properties of porous media. Colorado State University, Hydrological paper No. 3, 27.

Campbell G.S. (1974). A simple method for determining unsaturated conductivity from moisture retention data. Soil Sci. 117: 311314.

Campbell G.S. (1985). Soil Physics with BASIC: Transport Models for Soil-Plant System,
Elsevier, Amsterdam, 150.

Cornelis W.M., Ronsyn J., Meirvenne M.V. and Hartmann R. (2001). Evaluation of pedotransfer functions for predicting the soil moisture retention curve. Soil Sci. Soc. Am. J. 65: 638-648.

Donatelli M., Acutis M. and Laruccia N. (1996). Evaluation of methods to estimate soil water content at field capacity and wilting point. Proc. of the 4th European Society of Agronomy Congress, Veldhoven, The Netherlands, 86-87.

EPIC/ASW. EPIC/ASW utility in EPIC Util source code, TAES, Temple, Texas.

Gee G.W. and Bauder J. (1986). Particle size analysis. In: Klute, A. (Ed.), Methods of Soil Analysis. Part 1. Physical and Mineralogical Methods. ASA, Madison, WI, 383-411.

Givi J., Prasher S.O. and Patel R.M. (2004). Evaluation of pedotransfer functions in prediction the soil water contents at field capacity and wilting point. Agri. Water Mange. 70: 83-96.

Gupta S.C. and Larson W.E. (1979). Estimating soil water characteristic from particle size distribution, organic matter percent, and bulk density. Water Resour. Res. 15: 1633-1635.

Hansen V.E., Israelsen O.W. and Stringham G.E. (1980). Irrigation Principles and Practices, $4^{\text {th }}$ ed. Wiley, NY.

Hastie T., Tibshirani R. and Friedman J. (2001). The Elements of Statistical Learning: Data Mining, Inference and Prediction, Springer, Berlin.

Hutson J.L. and Cass A. (1987). A retentivity functions for use in soil water simulation models. J. Soil Sci. 38: 105-113.

Hutson J.L. and Wagenet R.J. (1992). LEACHM, Leaching Estimation and Chemistry Model. Department of Soil, Crop and Atmospheric Sciences Research series no. 92.3. New York, Cornell University, 121.

Kern J.S. (1995). Evaluation of soil water retention models based on basic soil physical properties. Soil Sci. Soc. Am. J. 59:1134-1141.

Kobayashi K. and Salam M.U. (2000). Comparing simulated and measured values using mean squared deviation and its components. Agron. J. 92:345-352.

Mayr T. and Jarvis N.J. (1999). Pedotransfer function to estimate soil water retention parameters for a modified Brooks-Corey type model. Geoderma 91: 1-9.

Minasny B., McBratney A.B. and Bristow K.L. (1999). Comparison of different approaches to 
the development of pedotransfer functions for water-retention curves. Geoderma 93:225-253.

Mualem Y. (1976). A new model for predicting the hydraulic conductivity of unsaturated porous media, Water Resour. Res. 12:513522.

Nemes A., Schaap M. and Wösten H. (2002). Validation of international scale soil hydraulic pedotransfer functions for national scale applications, Symposium no. 04, paper no. 934, 14-21 August, Thailand.

Nemes A., Schaap M.G., and Wösten J.H.M. (2003). Functional evaluation of pedotransfer functions derived from different scales of data collection. Soil Sci. Soc. Am. J. 67: 10931102.

Pachepsky Ya.A., Timlin D. and Varallyay G. (1996). Artificial neural networks to estimate soil water retention from easily measurable data. Soil Sci. Soc. Am. J. 60:727-733.

Rawls W.J. and Brakensiek D.L. (1989). Estimation of soil water retention and hydraulic properties. In: S. Morel, Editor, Unsaturated Flow in Hydrologic Modeling. Theory and Pratice, Kluwer academic publishers: 275-300.

Rawls W.J., Brakensiek D.L. and Saxton K.E. (1982). Estimation of soil water properties. Trans. of the ASAE 25, 1316-1320.

Ritchie J.T., Gerakis A. and Suleiman A.A. (1999). Simple model to estimate fieldmeasured soil water limits. Trans. ASAE 42(6): 1609-1614.

Schaap M.G. and Bouten W. (1996). Modeling water retention curves of sandy soils using neural networks. Water Resour. Res. 32:30333040.

Schaap M.G. and Leij F.L. (1998). Using neural networks to predict soil water retention and soil hydraulic conductivity. Soil Tillage Res. 47: 37-42.

Schaap M.G. and Leij F.L. (2000). Improved prediction of unsaturated hydraulic conductivity with Mualem-van Genuchten model. Soil Sci. Soc. Am. J. 64:843-851.

Schaap M.G., Leij F.L. and van Genuchten M.Th. (1998). Neural network analysis for hierarchical prediction of soil hydraulic properties. Soil Sci. Soc. Am. J. 62:847-855.

Schaap M., Muller K. and ten Brink H.M. (2001). Constructing the European aerosol nitrate concentration field from experimental data. ECN-report RX-01-033, ECN, Petten, the Netherlands.

Sys C., Van Ranst E. and Debaveye J. (1991). Land Evaluation. Part I, Genral administration for Development Cooperation, Brussels, Belgium

Tietje O. and Hennings V. (1996). Accuracy of the saturated hydraulic conductivity prediction by pedotransfer functions compared to the variability within FAO textural classes. Geoderma 69: 71-84.

Tietje O. and Tapkenhinrichs M. (1993). Evaluation of pseudo-transfer functions. Soil Sci. Soc. Am. J. 57:1088-1095.

Tomasella J., Pachepsky Ya., Crestana S. and Rawls W.J. (2003). Comparison of two techniques to develop pedotransfer functions for water retention. Soil Sci. Soc. Am. J. 67:1085-1092.

van Genuchten M.Th. (1980). A closed-form equation for predicting the hydraulic conductivity of unsaturated soils. Soil Sci. Soc. Am. J. 44: 892-898.

Vereecken H., Maes J., Feyen J. and Darius P. (1989). Estimating the soil moisture retention characteristics from texture, bulk density and carbon content. Soil Sci. 148:389-403.

Walkley A. and Black A. (1934). An examination of the Degtjaeff method for determining soil organic matter, and a proposed modification of the chromic acid titration method. Soil Sci. 37: 29-38.

Wösten J.H.M., Lilly A., Nemes A. and Le Bas C. (1999). Development and use of a database of hydraulic properties of European soils. Geoderma 90:169-185.

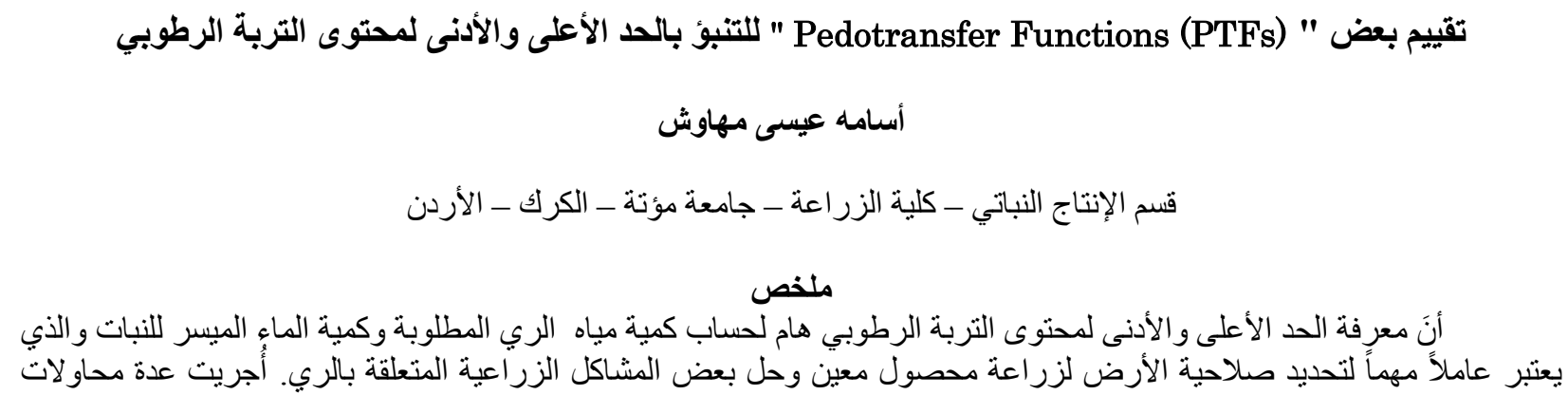


لإيجاد علاقة بين المعلومات المتوفرة عن بعض خصائص التربة الطبيعية والتي يمكن توفيرها بسهولة مثل نسجه التربة ( التوزيع

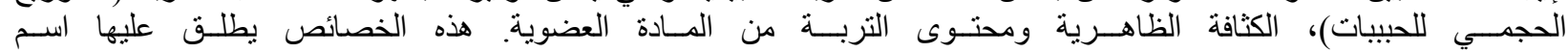
.Pedotransfer Functions( PTFs )"

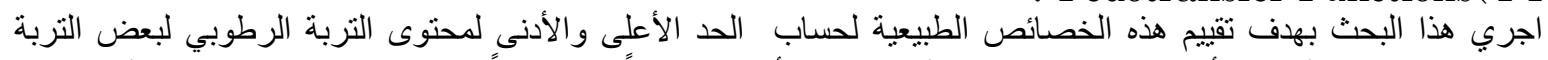

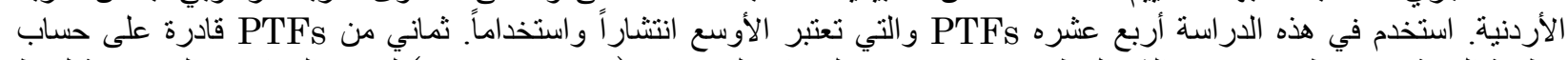

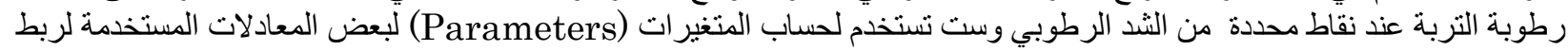

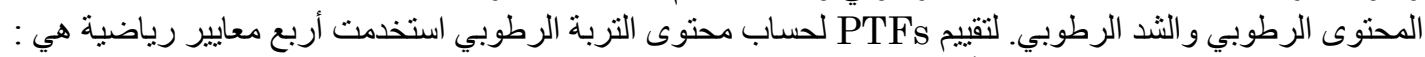

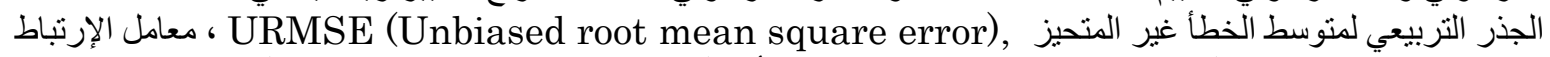
r، و الجذر التربيعي لمتوسط الخطأ (Correlation coefficient), الخطأ ME (Mean error) أظهرت النتائج المحسوبة بو اسطة PFTs عند مقارنتها بالنتائج المقاسة في المختبر تو افق ضـعيف إلى جيد. تر اوحت قيم المعايير

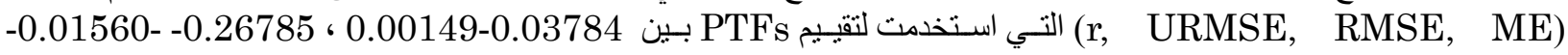

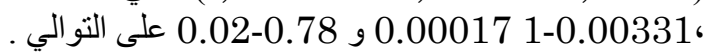
بناءً على المعايير المستخدمة، أظهرت النتائج أن أفضل PTFs لحساب الحد الأعلى والحد الأدنى للمحتوى الرطوبي للترب التي

أجري عليها الاختيار هي: . British soil survey (topsoil and subsoil) and Rawls-Brakensiek PTFs

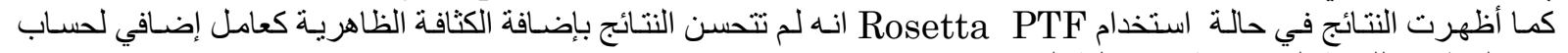

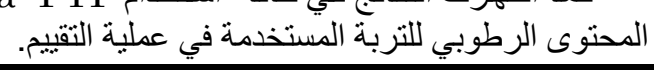

المجلة العلمية لكلية الزر اعة - جامعة القاهرة - المجلد(59) العدد الثالث ( يوليو 2008):249-258. 